\title{
The Economic Impact of Climate Change on Transportation Assets
}

\section{Gelete $\mathrm{G}^{*}$ and Gokcekus $\mathrm{H}^{2}$}

${ }^{1}$ Department of Civil Engineering, Near East University, Nicosia, northern Cyprus, Turkey

${ }^{2}$ Faculty of Civil and Environmental Engineering, Near East University, Nicosia northern Cyprus, Turkey

*Corresponding author: Gebre G, PhD Scholar, Department of Civil Engineering, Near East University, Nicosia, Northern Cyprus, Turkey, Tel: 05338550396, E-mail: gegelete04@gmail.com

Citation: Gelete G, Gokcekus H (2018) The Economic Impact of Climate Change on Transportation Assets. J Environ Pollut Control 1(1): 105. doi: 10.15744/2639-9288.1.105

Received Date: June 03, 2018 Accepted Date: September 12, 2018 Published Date: September 14, 2018

\begin{abstract}
Climate change is the statistical distribution changes of weather patterns when that change lasts for a long period. This paper aims to review economic wide effect of climate change on transportation assets. Climate change economically affects transportation by increasing maintenance, operation, rehabilitation, and repairmen costs of transportation infrastructure. Climate changes can also increase the cost of new transportation infrastructure due to higher climate adaptable design standards. It also accelerates infrastructure replacement costs. In addition to damage to transportation infrastructures, climate change can also indirectly cause loss of infrastructure service and activity disruption. Climate change also causes bring down travel times, higher cost choice required to address operational needs and accumulating yield for shipment when transport courses allow.
\end{abstract}

Keywords: Climate Change; Impact; Transportation; Economic

\section{Introduction}

According to IPCC (2010) defines climate change as statistical distribution changes of weather patterns when that change lasts for a long period, typically decades or longer [1]. Climate change and its impact are becoming a warning issue during the $21^{\text {st }}$ century and has become the predominant issue of our time. Almost all manmade and natural resources and frameworks are at a potential danger of being negatively influenced by the changes brought by a new climate change regime (IPPC, 2007b) [2]. Be that as it may, the degree to which climate change speaks to an issue is as yet a vigorously faced off regarding the issue; computations of climate change harm for the future, and judgments about adjustment and alleviation expenses to be made currently, varies generally. For example, Stern (2007) reports that the advantage of taking solid early measurement considerably exceeds the expenses from climate change.

Infrastructure is the backbone of social and economic development. Especially transportation infrastructure is responsible for the development of civilizations from ancient times for transporting the required goods and meeting the travel requirement of people. This is because transportation systems increment the flow of people and products, reinforce provincial connections, give access to fundamental wellbeing and social administrations, and enhance economic improvement (Dave 2014) [3]. However, it is profoundly affected by climate change.

Climate change and transportation sector are uniquely related one is the cause, and the other is the effect and vice versa. Several studies have examined the contribution of aviation, land, and marine transport to climate change through the emission of greenhouse gasses to the atmosphere (International Energy Agency, 2008; IMO, 2008) [4,5]. Transportation sector contributes about $26 \%$ of the total global carbon dioxide emissions and is one of the few industrial sectors where emissions are still growing (Lee, 2007) [6]. Extreme weather events such as hurricanes, thunderstorm, storm surge, flooding, lightning, and rise in sea level has adverse impacts on the transport system (Nemry and Demirel, 2012; Koetse and Rietveld, 2009; Regmi and Hanaoka, 2011) [7-9].

There is sufficient knowledge on how the transportation sector can contribute to climate change through emissions. However, comparatively less research was conducted on the adverse effect of global warming on the functioning of transportation. However, less attention has been given to the consequences of potential climate changes for designing, planning constructing, and operating the transportation infrastructure (ECLAC, 2011) [10]. Even from the studies conducted on climate change impact on transportation most of them focus on its physical impact. Despite their relevance, comprehensive studies of climate change effect of on the economics transportation system are rare. In this manner, this paper aims to review the economic effect of climate change on transportation sectors. 


\section{The Economic Impact on Different Mode of Transportation}

Climate change and transportation have a unique relationship. That means transportation infrastructure is both the driver of and driven by climate change. Transportation sector contributed about $24 \%$ of the global $\mathrm{CO}_{2}$ production during 2003 . For organization economic cooperation and developed countries members, this share was even more than 29\%. From different transportation methods, road transport contributes from $18 \%$ to $23 \%$ for worldwide, whereas aviation was responsible for two third of carbon dioxide emissions (Werner, 2010) [11]. In the rich countries the share of aviation, land transportation, and marine transport is even higher. Particularly, $\mathrm{CO}_{2}$-emissions from aviation have been dramatically increased in the past 15 years. Carbon dioxide emissions were grown by $87 \%$ in the European Union from 1991 up to 2003 . Besides, $\mathrm{CO}_{2}$ emissions make up only $50 \%$ of greenhouse gases produced by air transportation sector.

The design, construction, and operation of transportation are weather dependent. Climate change affects the transportation sector in many ways such as permanent or temporary flooding of bridges, roads, and ports. Climate change can also increase maintenance costs by causing damage to transport infrastructure or increased wear and tear; and increasing the frequency and length of service disruption. It is clear that a reliable transportation is very important for economic development and to have healthy communities. As a result of its effect on transportation infrastructure, climate change could have far-reaching implications for development programs, particularly those that depend on transportation to gain access to the populations they serve (USAID, 2013) [12]. Alteration in precipitation and temperature because of climate change can also have an unfavorable effect on various methods of transportation resources.

Climate change profoundly affects all modes of transportation. According to Gabriel (2016), because of environmental change, transportation systems are required to become progressively worried by outrageous climates such as rise in sea level, flooding, storm surge and lightning, bringing about direct expenses inside the influenced parts and also indirect expenses from sectorial inter-linkages [13]. Climate change also increases the cost of designing, operation, construction, maintenance, rehabilitation, and repairmen costs of transportation infrastructure (Abdul, 2015) [14]. According to his study, climate change can also cause modification and change of existing flood protection and hydraulic structures measures. Moreover, extra new water powered structures or surge assurance measures are required to deal with the potential effects of climate change. According to Daniel et al. (2015) modification of the existing hydraulic structure and construction of new flood protection structures increase cost. Gordon et al. (2010) studied the cost of adopting transportation infrastructure for climate change which was commissioned by the World Bank [15]. They concluded that climate change increases the costs of new transport infrastructure because of expensive construction materials to handle the effect and higher climate adaptable design standards.

The other economic impact of climate change is that it causes delay, disruption or closure of transportation. Michael and Marko (2013) study the economic effect of extreme weather and European aviation [16]. They concluded that extreme weather like flooding; extreme temperature, hurricane, and sea level rise causes disruptions in transport network operation and services affecting normal economic activities and losses thereof.

\section{Impact on land-based transportation}

Economic impact on road infrastructure: The road transport infrastructure has vast economic importance. Currently, roads are carrying about $70 \%$ of the goods, and the trend is rising (Ickert et al., 2007). However, climate change adversely affects road infrastructure in many ways. Increasing temperatures due to climate change causes asphalt roads to effortlessly create breaks inside a brief short period of time after their construction. Also, high precipitation makes the new roads to create potholes while the existing one will deepen rapidly and easily (Djei-Mantey, 2014) [17]. Increased temperature in combination with higher solar radiation energy may shorten the service life of black-top road surfaces (Taylor and Philp, 2011) [18]. In this manner, poor roads resulting from substantial climate-induced potholes results in car crashes and causes the vehicle of foodstuffs and merchandise to be delayed across the whole country vehicular congested driving conditions can prompt more fuel utilization notwithstanding considerable time misfortune (Daniel et al., 2015). For example, Ghana suffered from the adverse climate change impacts on the transportation sector. EPA (2010) indicated that in Ghana 1,016 km of feeder streets destroyed, 13 bridges were collapsed and four hundred forty two culverts were destroyed in the northern district during 2007 due to extreme weather events [19].

Temperature in the earth surface will increase by $2^{\circ} \mathrm{C}$ in 2050 . Schiermeier (2006) also estimates that global temperatures are likely to rise from $2.5^{\circ} \mathrm{C}$ to $4.0^{\circ} \mathrm{C}$ by 2100 . However, IPCC (2007b) estimated that global temperature will rise from one point four $(1.4)^{\circ} \mathrm{C}$ up to five point eight $(5.8)^{\circ} \mathrm{C}$ by the year 2100 . In any scenario criteria, climate change will potentially increase in the future. Paul et al. (2014) have studied the potential temperature on the road in three southern African countries (Malawi, Mozambique, and Zambia) [20]. The study concluded that these three countries are facing a potential \$596 million price tag for maintaining and repairing roads damaged directly related to precipitation and temperature changes from potential climate change through 2050. IPCC has also studied the future economic effect of change in climate on Boulder County's road infrastructure and concluded that the total increase in maintenance costs by 2030 would be $\$ 183$ million than the current condition. Daniel et al. (2015) estimated the cost of road infrastructure construction, repairmen and maintenance in Ghana from 2020 up to 2100 by using the stressorresponse method. According to their study, it could cost Ghana about $\$ 473$ million to keep up and repair damage to existing 
roads because of environmental change impact (without adaptation scenario). Another study conducted in Australia by Gabriel (2015) also showed that the total costs of road repairers due to climate change were sum up to $€ 47$ million per year. According to Abdul (2015), the USA spends 20\% more on aviation and highway infrastructure maintenance or nearly $\$ 15$ billion per year for the present level of service [14]. Likewise, the European Union spends around 1.8 billion euro per year for weather-induced road transport. In addition to a direct economic cost in the transportation sector, people have been losing their precious life due to a weather-induced road accident.

Françoise (2012) researched the impact of climate change in five European countries (Italy, German, Belgium, the Netherlands and Spain) road and rail transport infrastructures [21]. This research concluded that extreme weather increases maintenance \& repair costs for the road by $30 \%$ up to $50 \%$ or 10 billion $€$ /year. Gabriel (2017) also studied the economic impact of climate change on land-based transportation in Australia. He found that the total the costs of the impact on the road transport sector were about $€$ 47 million per year. When analyzed across cost categories, the lion's share of costs is owing to harms to road infrastructure which is $€ 39$ million every year ( $82 \%$ of the aggregate). The second largest cost component was vehicles damage (€ 5 million per pear) which accounts for $10 \%$ of the total cost. With respect to impact categories, about $19 \%$ triggered by snow and ice, about $67 \%$ of the damage was activated by rain and surge, $8 \%$ by storm and $6 \%$ by extreme temperature. Françoise and Hande (2012) studied the economic impact of climate change on road transport in Europe [21]. They found that the current extreme weather damage costs on road transportation in France, middle Europe, UK and Ireland, Eastern Europe and Scandinavia were 133 million $€ /$ year, 73 million $€ /$ year, 59 million $€ / y, 29$ million $€ /$ year, 153 million $€ /$ year respectively.

The other climatic factor which profoundly threatens road infrastructure is extreme precipitation which results in flooding. According to (Daniel et al., 2015) high precipitation and flooding will allow new roads to develop potholes while existing potholes will deepen fast easily. For example, Francisco (2012) found that winter cracking and potholes in five European countries namely Italy, Spain, Belgium, German and the Netherlands is due to the joint effect of deep frost and thaw-freezing cycle effects and also the function of precipitation [21]. According to his study, the maintenance cost for pothole and cracking road due to precipitation was 500 to 170 million $€$ /year. EPA (2010) also indicated that the Accra floods in 2009 practically rolled off the asphalt on the Kaneshie Highway while flooding in Swedru thoroughly washed away parts of the main road in the town. According to (DjeiMantey, 2014), due to this flood about \$44.2 million was incurred in the greater Accra region of Ghana [17]. Madan (2009) studied the impact of the flood in Bangladesh and concluded that the damage done to the road transport infrastructure by 2007 floods was \$363 million. The Aceh flood in 2007 in Indonesia made huge harm the to the transportation sector amounting to the \$35 million every year. According to Françoise (2012), five European countries spend 0.65 billion €/year due to heavy rainfalls \& floods [21].

Sea level rise (SLR) is a vital component of understanding the changing climate impact on infrastructure in countries with coastal areas (Nicholls and Cazenave, 2010) [22]. Sea level rise can flood unpaved and graveled roads adjacent to the seashore. If sea level rises by $1 \mathrm{~m}$ in Europe will costs $€ 18.5$ billion (Françoise and Hande, (2012) [21].

Impact on rail transportation infrastructure: Climate change together with extreme weather condition such as temperature, sea level rise and precipitation affects the operability of transportation infrastructure. Railway tracks are usually designed to withstand a sensible flood and temperature range (Chapman et al., 2005) [23]. Rising temperatures beyond this range may prompt material pressure, including clasped rails (Posey, 2012) [24]. Duinmeijer and Bouwknegt (2004) studied the adverse effect of weather conditions on rail transportation infrastructure failures in Netherlands in the year 2003 [25]. It creates the impression that roughly 5 to $10 \%$ of all failures were climate-related. A large portion of the climate-related failures are caused by storm, high temperatures, lightning, icing, and storm (Koetse and Rietveld, 2007) [26].

August 2003 was an extraordinary month amid an unusual hot summer in United Kingdom and made a lot of damage transportation framework (Burt, 2004) [27]. For the railways in the UK, the damage caused was the most exceedingly terrible seen since summer 1995, where there were a comparative number of clasps, 137 out of 2003 and 133 of every 1995, contrasted and the normal 30 - 40 for each annum. As indicated by Daniel (2017), the present normal yearly climate-induced costs in the rail transportation in Australia were $€ 18$ million. Out of the total cost, about $88 \%$ attributable to infrastructure and the remaining $12 \%$ attributed to vehicles, user, and service. With regard to the cause of damage, around $95 \%$ of all rail way damages were activated by surge and rain. Vehicle damages are activated predominantly by surge and rain (70\%) and also a tempest (20\%).

\section{Impact on marine transportation}

According to USGCRP (2014), climate changes will probably affect water transportation infrastructure and logistics both positively and negatively [28]. For instance, an increase in temperatures lessened ice cover on lakes and streams in different locales of the world, as appeared in river Canada and Russia (Lee, 2007) [6]. It opens up possibilities for increased transport. Lofgren et al. (2000) studied the impact of climate change on domestic shipping and reasoned that there is a beneficial outcome of unnatural global warming brings about a significant diminishment in ice cover on the Great Lakes in Canada [29].

As indicated by PIAFNC (2008), another result of global warming is the diminishment of ice around the North Pole. According to Birchall (2006), this may increase the likelihood of ocean transport on the Northwest Passage for no less than a while every year [30,31]. This course may give chances to more effective transport between Europe, North-America, Asia, and Russia. 
The adverse effect of climate change on marine transport is that it damages ships, ports, and harbors. Like other coastal infrastructure, harbor offices, including docks and extensions, must be raised and strengthened to oblige higher tides and tempest surges as sea levels rise (NRC, 2008) [32]. Changes in precipitation can influence transporting from numerous points of view. Flooding could close delivering channels, and expanded spillover from extraordinary precipitation occasions could make residue and garbage develop, prompting shallower and less open channels (USGCRP (2014) [28]. According to Cruce and Yurkovich (2011), shipping is becoming very sensitive to lower water levels as an annual mean or during periods of seasonal variation [33]. A thousand foot vessel loses 270 tons of limits for each inch of the lost draft, which is proportionate to about $\$ 30,000$. In the United States, for instance, low water levels from 1997 and 2000 constrained shippers to lessen load tonnage by 5\% to 8\%. Research directed by Millerd (2007) demonstrated that falling water levels are required to increment working expenses by $1.9 \%$ to $7.4 \%$ by 2030 , with costs anticipated to increment in the vicinity of $13.3 \%$ and $26.7 \%$ before the centuries over [34]. Posey (2012) likewise assessed the economic loss of low water level on shipping and found that cost will ascend in the vicinity of $5 \%$ and $22 \%$ by 2030 . Cruce and Yurkovich (2011) additionally presumed that falling of water levels could harm port and marine infrastructure and increment digging costs [33]. Defra (2012) likewise examined the impact of atmosphere changes on marine transportation in Scotland. The investigation presumed that for marine transport interruption to shipping administrations working off could increment from $5 \%$ at present to $12 \%$ by 2020 . There is likewise expanded danger of harm to port infrastructure, put away freight and transport systems because of flooding.

\section{Impact on Air Transportation}

Climate change affects the transportation sector by directly affecting air travel or air transporting infrastructure. Different huge atmospheric variables result in serious air catastrophes and regular flight plan interruptions. The essential atmospheric perils are lightning, rainstorms, icing, hail, wind shear, overwhelming precipitation, and low cloud. Extreme weather condition causes damage to aircraft and loss of life. Among the many modes of transportation, aviation is highly weather dependent. Times of extraordinary warmth can influence flying machine execution and may make airplanes confront freight limitations, flight postponements, and retractions. However, hotter climate in winter will lessen the requirement for airplane deicing (USGCRP, 2014) [28]. Storms constrained whole airports to close, as happened along the Gulf Coast amid Hurricane Katrina and all through the Northeast amid Hurricane Sandy (NRC, 2008 and USGCRP, 2014) [28,32].

\section{The Economic Cost of Delay and Cancelation of Transportation}

The other economic impact of climate change and extreme weather is transportation delay. Extreme weather-induced transportation delay and disruption is not only a painful inconvenience for the actors, but delays also induce considerable costs, for the airlines, their customers and the community as a whole (ITA, 2000) [35]. The present-day adverse weather conditions effect estimated in the UK causes $20 \%$ of all unplanned postponements which is identical to 5 million delay minutes (Thornes and Davis, 2002) [36]. In 2003 in the UK there was extreme heat during summer which resulted in buckling and hence 130000 delayed minutes in transportation. According to Burt (2004), the cost of this 130,000 extra differ minutes caused was $£ 2.2$ million, which gives a normal cost of $£ 16.70$ per postpone minutes [27]. According to Charisse (2015), in the USA the cancellation of several flights in most of recent winter storm costs the travelers and airplanes almost $\$ 200$ million. As indicated by this report Boston, Chicago, and New York, was enduring the worst part of the excess of 6,000 flights dropped on February second, 2015. This cancellation of flight costs the airline at any rate $\$ 16$ million as they pay team individuals who are as of now set up, offer discounts to travelers who pick not to reschedule abandoned treks, and record for different costs and lost income.

The other cost incurred due to transportation cancelation or delay is the Social cost. It is the passengers' experienced delay from delayed or canceled flights, measured through the value of time (Michael and Marko. 2013) [16]. According to this study, if 10\% of the average movements per day are affected in European aviation, then the social cost will be $€ 828.177$.

\section{Cost of Adapting Transportation Infrastructure for Climate Change}

Regarding adaptation, there are diverse adaptation measures which are actualized in the road and rail transport segments to decrease climate change impacts (Daniel, 2017). As to road transport segments, the main measure is the expansion of drainage framework close by roads by $20 \%$. In Australia for example, expanding drainage system to protect transportation infrastructure costs with total investment costs of $€ 130$ million (Altvater et al., 2012) and yearly costs of $€ 4$ million (accepting 30 years until full devaluation) [37]. The other adaptation measure is planting tree which also incurs cost. For example, in Australia vegetation alongside streets is increased by $20 \%$, prompting yearly workforce expenses of 14 milion euro and 7 milion euro material expenses (ACA, 2013) [38]. The other adaptation strategy is to use more expensive and robust material during the construction of transportation infrastructure to withstand the current climate change impact. This method also increases costs compared to the normal condition. Daniel et al. (2015) studied the monetary effect on road infrastructure adjustment in Ghana for climate change. According to this study, the cost was $\$ 473.72$ million under no adaptation scenario and $\$ 678.47$ million under adaptation scenario. The Global Business Travel Association (2011) studied the impact of extreme weather on flight delay of corporate travel in the USA. It was discovered that there was an average daily loss of 58 million US dollar in business travel spending in every state [38]. 


\section{Conclusion}

The unique relationships between climate change and transportation infrastructure are that one is the cause and the other is the effect and vice versa. Transportation sector is both a contributor to global warming and a victim of climate change. That means transportation sector is estimated to contribute 26 percent of the total greenhouse gas emission to the atmosphere. On the other hand, climate change profoundly affects the design, construction, and life of transportation infrastructure.

Climate change affects transportation in many ways. Higher temperature because of environmental change makes road asphalt mellow and grows. This in turn makes road rutting and pothole particularly in high rush hour gridlock zones and can put bridge pressure. High temperatures again increase the repairmen and replacement cost of transportation infrastructure. At the point when presented to the high temperatures, railway tracks may create warm crimps causing track misalignments, or supposed clasp, which can thus cause prepare crashes and damage to prepare and loss of life. Extreme warmth can influence aircraft execution and may make airplanes confront flight postponements, scratch-offs, and cargo confinements. Extreme temperature can also positively affect marine transportation in such a way that it reduces ocean ice and extend shipping season.

\section{References}

1. Solomon S, Qin D, Manning M, Chen Z, Marquis M, et al. (2010) Climate Change: The Physical Science Basis. The contribution of workgroup I to the IPCC. Cambridge University Press, Cambridge, United Kingdom.

2 Parry ML, Canziani O, Palutikof J, Linden PJ, Hanson C (2007) Climate Change 2007: Impacts, Adaptation, and Vulnerability. The contribution of Working GroupII to the Fourth Assessment Report of the IPCC. Cambridge University, Cambridge, UK.

3. Dave Sawyer (2014) The Economic implications of climate change on transportation assets: An analysis framework.IISD report. Published by the International Institute for Sustainable Development.

4. International Energy Agency (IEA) (2008) CO2 Emissions from Fuel Combustion (2008 Edition), Paris, France, Organization for Economic Co-operation and Development (OECD).

5. International Maritime Organization (IMO) (2008) Updated Study on Greenhouse Gas Emissions from Ships.

6. Chapman L (2007) Review of Transport and climate change. J Trans Geograp 15: 354-67.

7. Nemry F, Demirel H (2012) Impacts of climate change on transport: a focus on road and rail transport infrastructures (No. Report EUR 25553 EN), JRC Scientific and Policy Reports. Joint Research Center, Luxembourg.

8. Koetse MJ, Rietveld P (2009) The impact of climate change and weather on transport: an overview of empirical findings. Transportation Research Part D: Transport Environment 14: 205221.

9. Regmi MB, Hanaoka S (2011) A survey on impacts of climate change on road transport infrastructure and adaptation strategies in Asia. Environ Econ Policy Stud 13: 21-41.

10. Economic Commission for Latin America and the Caribbean (ECLC) (2011) The assessment of the economic impact of climate change on transportation sectors in Barbados.

11. Rothengatter W (2010) Climate change and the contribution of transport: Basic facts and the role of aviation. Transportation Research Part D: Transport and Environment 15: 5-13.

12. USAID (2013) Addressing climate change impact on the infrastructure of the USA. Fact sheet.

13. Bachner G (2016) Assessing the economy-wide effects of climate change adaptation options of land transport systems in Austria. Reg Environ Change 17: 92940.

14. Quium A (2015) Transport Infrastructure Adaptation to climate change and extreme weather impacts. Regional Seminar on Safe, Climate Adaptive and Disaster Resilient Transport for Sustainable Development 17-18 November, Kathmandu, Nepal.

15. Gordon H, Chinowsky P, Strzepek K (2010) The Costs of Adapting to Climate Change for Infrastructure. The World Bank, development and climate changed discussion paper in August 2010.

16. Michael K, Marco N (2013) Extreme weather and the European aviation- an economic perspective. 13th world conference on transport research, Rio de Janeiro, Brazil.

17. Adjei-Mantey K, Strzepek N, Twerefou D (2014) The economic impact of climate change on road infrastructure in sub-Saharan African countries. WIDER Working Paper No. 2014/032.

18. Taylor M, Philp M (2010) Adapting to climate change implications for transport infrastructure, transport systems, and travel behavior. Road Transportation Res 19: 66-79.

19. Environmental Protection Agency (2010) Climate Change in Ghana: Disaster Risks are an Increasing Concern for All; EPA Policy Advice Series No. 3; Environmental Protection Agency: Accra, Ghana.

20. Chinowsky PS, Schweikert AE, Strzepek NL, Strzepek K (2013) Infrastructure, and climate change: Impacts and adaptations for the Zambezi River Valley, WIDER Working Paper, No 2013/041.

21. Unit on Economics of Climate Change, Energy and Transport (2012) Impacts of climate change in Europe: A focus on road and rail transport infrastructures, The European Commission's, UK.

22. Nicholls RJ, Cazenave A (2010) Sea Level Rise and its Impact on Coastal Zones. Science 328: 1517-20.

23. Chapman L, Thornes JE, White SP (2005) Measurement, modeling and mapping to predict rail temperature, RSSB (2005).

24. Posey J (2012) Climate Change Impacts on Transportation in the Midwest. In: U.S. National Climate Assessment Midwest Technical Input Report. Great Lakes Integrated Sciences and Assessments (GLISA) Center, USA.

25. Duinmeijer AGB, Bouwknegt R (2004) Betrouwbarheid railinfrastractuur 2003 (Reliability of railway infrastructure, 2003) Prorail, Utrecht.

26. Koetse MJ, Rietveld P (2009) The impact of climate change and weather on transport: An overview of empirical findings, Transportation research part D 14: 205-21. 
27. Burt S (2004) Heat wave in the United Kingdom, the august 2003. Weather 59: 199-208.

28. Melillo, Jerry M, Terese T C, Richmond, Yohe G W (2014) Climate Change Impacts in the United States: The Third National Climate Assessment, USA

29. Lofgren BM, Quinn FH, Clites AH, Assel RA, Eberhardt AJ (2000) Great Lakes resources. In: Sousounis, P.J., Bisanz, J.M. (Eds.), Preparing for a Climate Change - Great Lakes Regional Assessment Group. University of Michigan, Ann Harbor

30. Permanent International Association for Navigation Congresses (2008) Waterborne transport, ports, and waterways: a review of climate change drivers, impacts, responses, and mitigation. In: EnviCom - Task Group 3, Permanent International Association for Navigation Congresses, Brussels.

31. Birchall SJ (2006) Canadian Sovereignty: Climate Change and Politics in the Arctic. Arctic 59:1-2.

32. NRC (2008) The potential impact of climate change on U.SA. Transportation Research Board Special Report 290. National Research Council (NRC).

33. Cruce T, Yurkovich E (2011) Adapting to climate change planning guide for state coastal managers a Great Lakes supplement. Silver Spring, MD, NOAA Office of Ocean and Coastal Resource Management, USA.

34. Millerd F (2011) The potential impact of climate change on Great Lakes international shipping. Climatic Change 104: 629-52.

35. ITA (2000) Cost of air transport delay in Europe, report.

36. Thornes JE, Davis B (2002) Managing effects of Weather on the Rail Network, Proc. of the 5th Rail Engineering Conference, London.

37. Altvater S, Block de D, Bouwma I, Dworak T, Frelih-Larsen A, et al. (2012) Adaptation measures in the EU: policies, costs, and economic assessment. Climate Proofing of key EU policies.

38. Austrian Court of Audit (ACA) (2013) Bericht des Rechnungshofes. Bauliche Erhaltung von Landesstraßen. Reihe Tirol.

39. United Nations framework convention on climate change (1992).

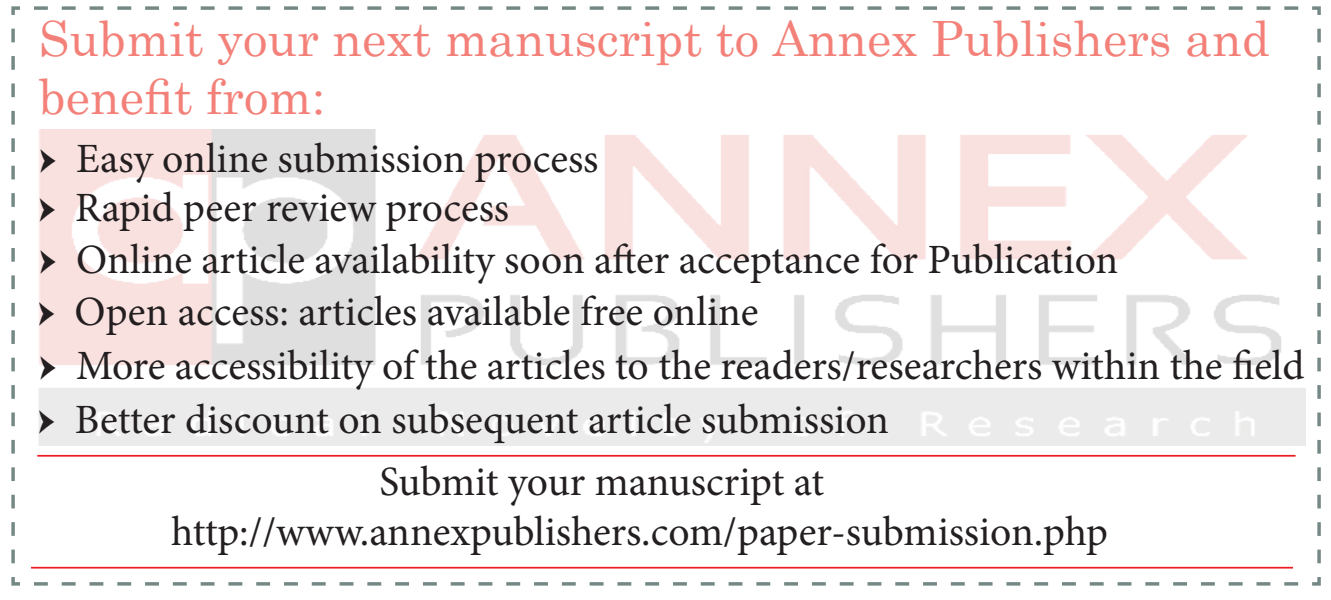

